\title{
Rare double orifice mitral valve
} malformation associated with bicuspid aortic valve in Turner syndrome: diagnosed by a series of novel three-dimensional echocardiography and literature review

\author{
Feifei Sun ${ }^{1 \dagger}$, Xueying Tan ${ }^{1 \dagger}$, Aijiao Sun ${ }^{1}$, Xintong Zhang ${ }^{1}$, Yanxiao Liang ${ }^{2}$ and Weidong Ren ${ }^{1 *}(\mathbb{D}$
}

\begin{abstract}
Background: Patients with both double orifice mitral valve (DOMV) and bicuspid aortic valve (BAV) malformation are rare. Although DOMV or BAV can be detected in some genetic syndromes, it has not been reported to simultaneously appear in Turner syndrome (TS). TrueVue, TouchVue, and TrueVue Glass are the latest technologies in advanced threedimensional echocardiography (3DE), which is an important information supplement to two-dimensional echocardiography (2DE) for the diagnosis of congenital cardiac malformations. Herein we report the novel use of the abovementioned technologies in the diagnosis and evaluation of a rare, combined valve malformation. Meanwhile, we also reviewed the literature for cases involving both DOMV and BAV and their association with various genetic syndromes.
\end{abstract}

Case presentation: We present the case of a 5 -year-old girl diagnosed with TS because of a developmental delay. DOMV and BAV were found through echocardiographic examination. Three-dimensional transthoracic echocardiography as well as a series of novel advanced techniques were applied to clearly display the spatial structure of all tiers of the mitral valve apparatus, aortic valve, and arch to facilitate an accurate diagnosis.

Conclusions: This is the first case in which both DOMV and BAV were associated with TS. Innovative TrueVue and TrueVue Glass offer unprecedented photographic stereoscopic images, while TouchVue technology greatly improved the ultrasonic diagnostic workflow and the diagnostic performance of rare valve malformations by adding virtual light sources to display realistic light-shadow effects.

Keywords: Double orifice mitral valve, Bicuspid aortic valve, Three-dimensional echocardiography, Congenital cardiac malformation, Turner syndrome, TrueVue, TrueVue Glass, TouchVue

*Correspondence: rwd0410@163.com

${ }^{\dagger}$ Feifei Sun and Xueying Tan have contributed equally to this work ${ }^{1}$ Department of Ultrasound, Shengjing Hospital of China Medical University, No. 36 Sanhao Street, Heping District, Shenyang 110004, China Full list of author information is available at the end of the article

\section{Background}

The double orifice mitral valve (DOMV) is considered a rare congenital heart malformation due to the abnormal embryonic development of the endocardial cushion and myocardium, characterized by a two-channel atrioventricular valve in the left ventricle and accounting for about $0.05 \%$ of all congenital heart diseases $[1,2]$. The two orifices of the mitral valve (MV) can be symmetrical 


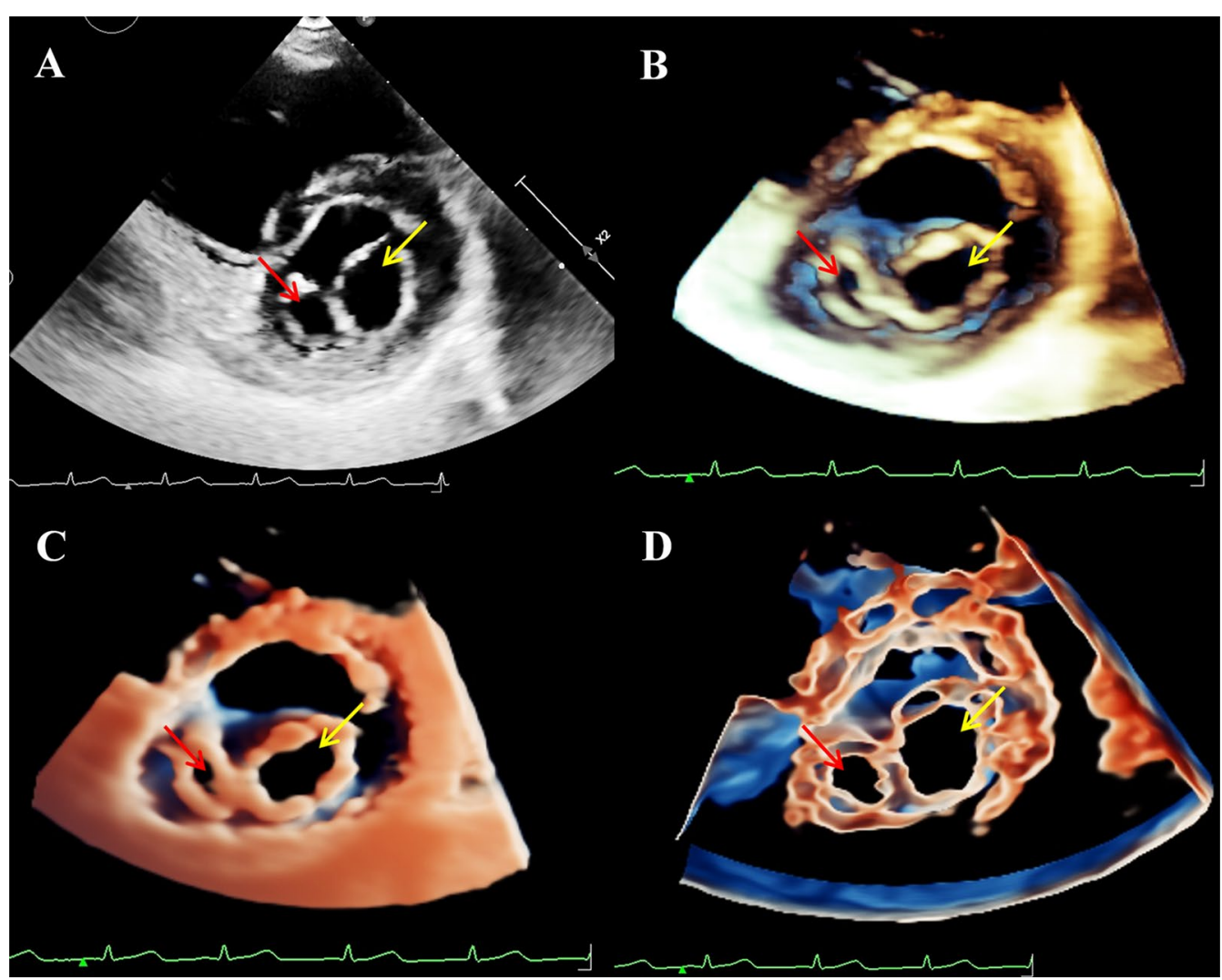

Fig. 1 Double mitral orifices. A-D 2D-TTE, traditional 3DE, TrueVue, and TrueVue Glass images showing double mitral orifices viewed in left ventricular short axis section (mitral valve orifice level). Yellow arrows show orifice 1, red arrows show orifice 2. 2D-TTE two-dimensional transthoracic echocardiogram, 3DE three-dimensional echocardiography

or asymmetrical, isolated or exist with other cardiac malformations, and can be divided into complete bride type, incomplete bridge type, or hole type [3, 4]. A bicuspid aortic valve (BAV) is relatively common and is characterized by the abnormal fusion of two leaflets of the aortic valve (AV) during development, resulting in a two leaflet valve instead of the normal tricuspid AV [5]. Patients with both DOMV and BAV are rare [6].

Turner syndrome (TS), known as congenital chromosomal disorder, is caused by the partial or complete deficiency of the $\mathrm{X}$ chromosome and is reported to have a higher incidence of congenital heart diseases, of which AV malformation is one of the most common changes $[7,8]$. Reported mitral malformations in TS are MV prolapse, myxomatous degeneration, parachute-like MV, cleft, and accessory leaflet [9-12]. To our knowledge, the occurrence of DOMV in TS has not been reported.

The two-dimensional echocardiography (2DE) is the most common and important method for detecting congenital heart valvular disease [13]. Meanwhile, the role of real-time three-dimensional echocardiography (RT-3DE) in the diagnosis and evaluation of congenital heart diseases has been receiving more attention due to its ability to show the overall spatial structure of the heart [14]. Several novel 3DE imaging technologies have been developed by Philips Medical System recently. TrueVue technology, which came out in 2019, is a new, high-resolution 3D echocardiographic imaging mode that can clearly display the subtle structure of the heart, which makes the ultrasound image more closely resemble the real anatomical pathology [15]. The TrueVue Glass, released globally in 2020, displays the myocardial tissue outside the heart cavity in a transparent mode, focusing on the cardiac cavity filled with blood flow, and can display the thin and translucent valves, which provides both a practical value and technological sense during the diagnosis and evaluation of heart diseases [16].

Here, we report a case with TS and congenital cardiac valvular malformations with DOMV and BAV, wherein we applied these advanced 3DE imaging technologies, which played an important role by providing images and diagnostic information that were previously unavailable. 


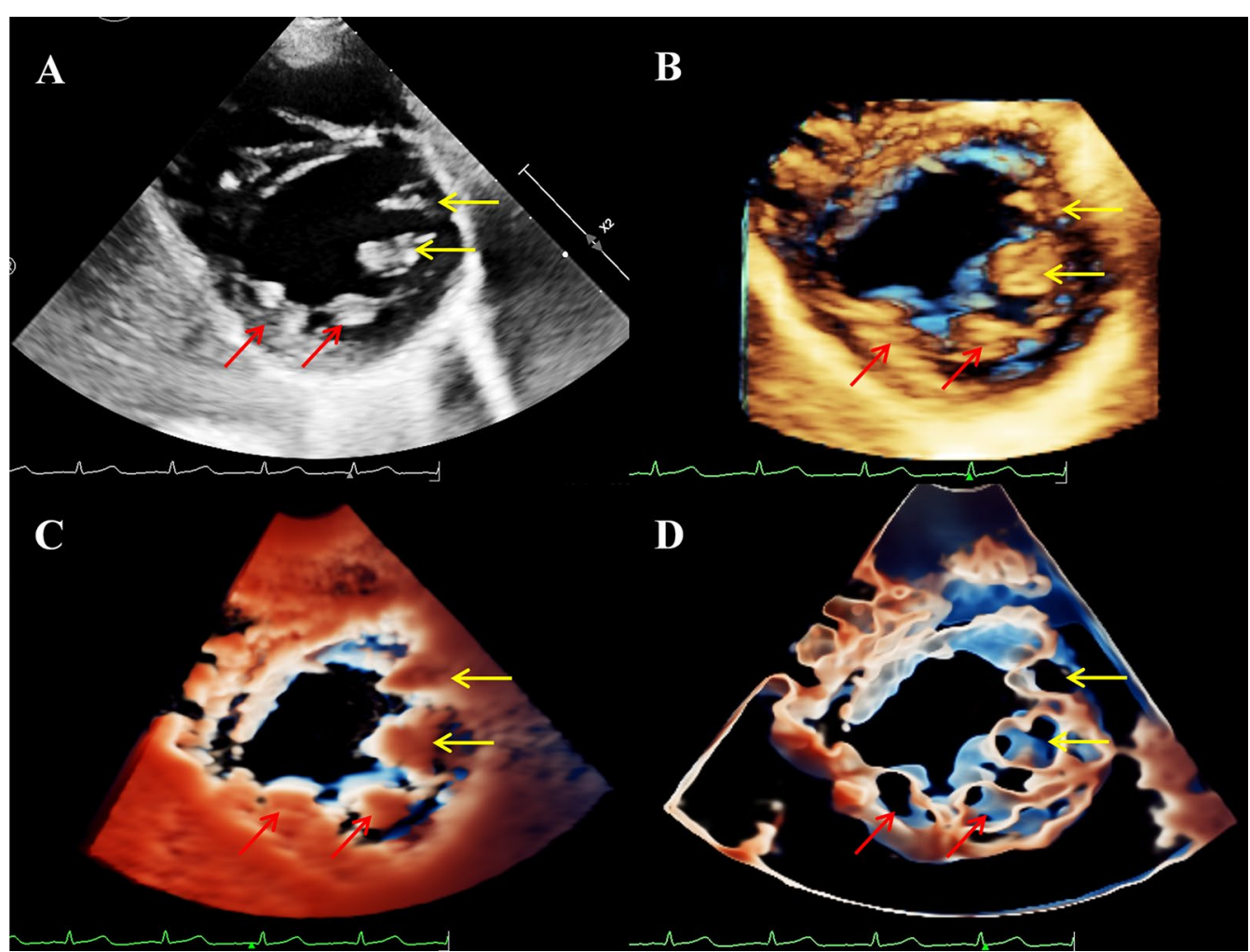

Fig. 2 Papillary muscles. A-D 2D-TTE, traditional 3DE, TrueVue, and TrueVue Glass images showing the four papillary muscles in the left ventricular short axis section (papillary muscle level). Yellow arrows show the papillary muscles of orifice 1, red arrows show the papillary muscles of orifice 2 of the mitral valve. 2D-TTE two-dimensional transthoracic echocardiogram, 3DE three-dimensional echocardiography

\section{Case presentation}

A 5-year-old girl presented to our hospital with a complaint of short stature and mild backache. She was found to have vitamin D deficiency, spina bifida, and small pituitary volume. Her peripheral blood chromosome result indicated " $45, \mathrm{X}$," consistent with TS.

To rule out developmental delay due to heart disease or cardiac abnormalities associated with TS, the transthoracic Echocardiogram (TTE) was performed using Philips EPIQ CVx cardiovascular specific ultrasonic diagnostic equipment (Philips Medical System, Andover, MA, USA). The 2DE scan application was conducted via a $59-2(2-9 \mathrm{MHz})$ probe. The $\mathrm{X} 5-1(1-5 \mathrm{MHz})$ probe was used for the 3DE examination. As diagnoses of both DOMV and BAV were suspected, the MV apparatus and AV-related structures were examined by 3D-TTE for further morphological and functional evaluation. On the basis of traditional 3D imaging, we launched the new TrueVue imaging mode. In TouchVue, in addition to being able to directly zoom and rotate the image with two fingers on the touch screen, more importantly, a single finger click on the target structure can display and move the position and depth of a virtual light source. Based on the TrueVue image, we further applied the Glass mode to obtain a transparent rendering effect. The short-axis view at the level of the MV via above-mentioned four techniques demonstrated that there were asymmetric double left atrioventricular orifices divided by a complete fibrous bridge, of which the anterolateral orifice was larger (Fig. 1). The total area of the two mitral orifices was about $2.17 \mathrm{~cm}^{2}$. At the level of the papillary muscle, four papillary muscles were revealed by 2D-TTE, traditional 3D-TTE, and TrueVue images, but were transparent and only the borders were revealed in the TrueVue Glass image (Fig. 2). The spatial relationship demonstrated that the two orifices were connected by their respective chordae tendineae, separating the two papillary muscles of the same side (Fig. 3). Color Doppler was superimposed, demonstrating two jets through the respective channels of the two orifices (Fig. 4). The real-time dynamic TrueVue Glass image can visualize the 3D blood flow through the thin and transparent valve (Additional file 1: Video 1). In this patient with MV malformation, we initiated the "dual volume" mode so that we could simultaneously observe two orifices on the left atrial view, four papillary muscles on the left ventricle view and the flow in two 


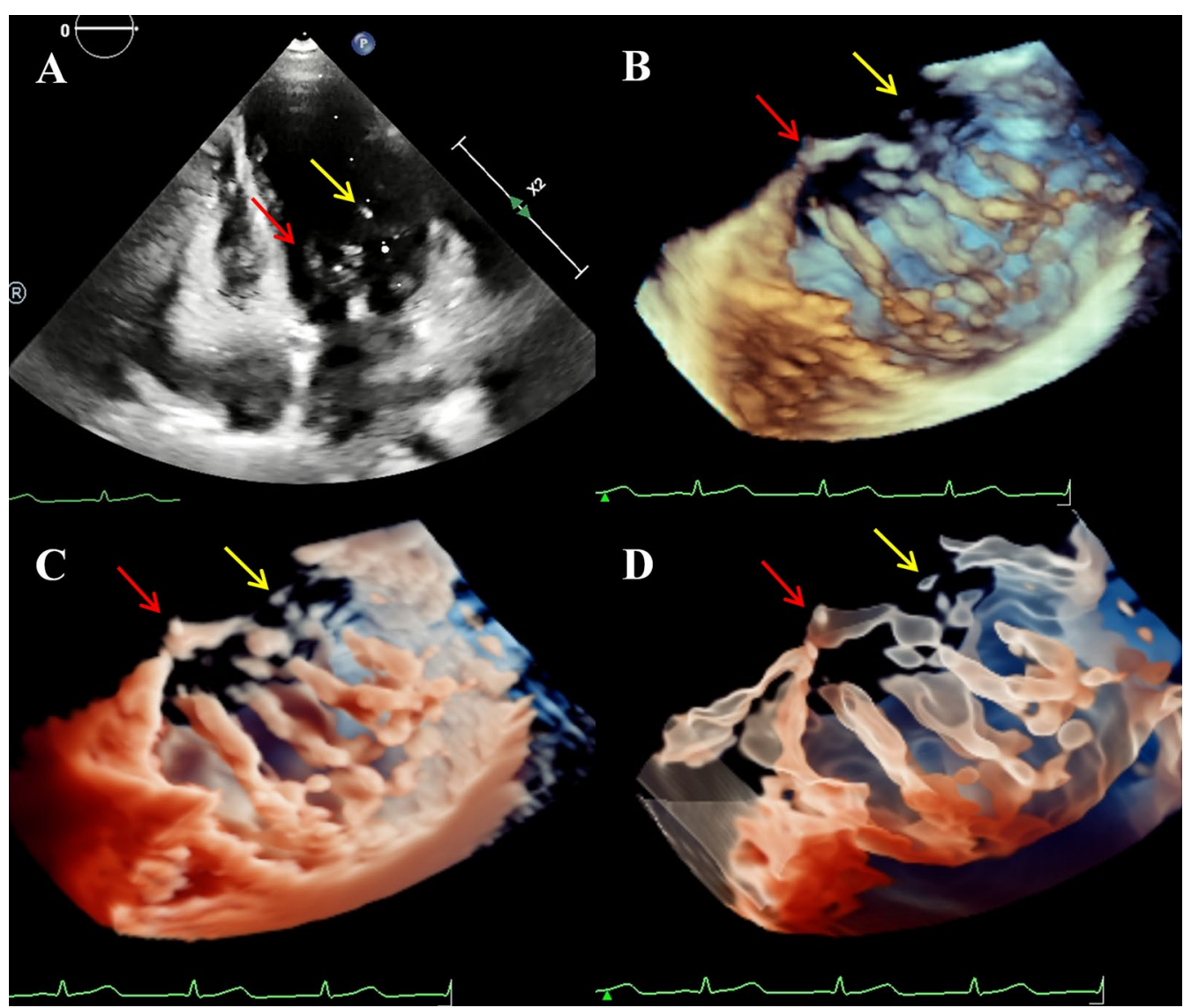

Fig. 3 Chordae tendineae. A 2D-TTE showing the long axis of the chordae tendineae. B-D demonstrate the spatial morphological characteristics of the chordae tendineae connecting the two orifices with the four papillary muscles of the mitral valve apparatus by traditional 3DE, TrueVue, and TrueVue Glass. Yellow arrows indicate chordae of orifice 1, red arrows indicate chordae of orifice 2. 2D-TTE two-dimensional transthoracic echocardiogram, 3DE three-dimensional echocardiography

opposite directions. (Additional file 2: Video 2). There was a slight increase in the forward blood flow velocity of the left atrioventricular valve orifices, the velocity in the early diastole was about $1.2 \mathrm{~m} / \mathrm{s}$, and in the late diastole was about $0.7 \mathrm{~m} / \mathrm{s}$. In addition, the short-axis view of the heart base revealed a BAV, with two leaflets in the left anterior and right posterior directions. We simultaneously compared the two-dimensional, traditional 3D, and new 3D TrueVue combined with the light and Glass mode imaging. Via TrueVue Glass imaging, when the light source was placed behind the valves, we observed a straight-line AV closure shape; the emergence of the coronary arteries and the spatial character of the aortic arch were also displayed simultaneously (Fig. 5). There was no aortic stenosis (peak systolic velocity is $1.3 \mathrm{~m} / \mathrm{s}$ ) or regurgitation, and the aortic arch descended to the left normally. Trivial mitral regurgitation was observed, but no other associated congenital cardiac abnormalities were detected. Surgical intervention was not performed for the time being because there was no significant regurgitation or stenosis. The results of the echocardiographic followup after three months, half a year, and 1 year showed that there was no obvious stenosis or insufficiency of the val ves.

\section{Discussion and conclusions}

We further reviewed 24 patients with both DOMV and BAV in 16 references from 1988 to 2020 (Table 1). These patients ranged in age from one month to 67 years old $(25.55 \pm 19.95)$, including $12(50.0 \%)$ adults, $10(41.7 \%)$ children or adolescents, and $2(8.3 \%)$ patients whose ages were not described. Overall, 15 (62.5\%) were male, 7 (29.2\%) were female, and 2 (8.3\%) were of undescribed gender. Except for 1 (4.2\%) case in which the specific DOMV type was unknown, all the other cases were of complete bridge type, and in patients with relevant record information, there was an even distribution of symmetrical and asymmetrical orifices. As for the dysfunction of the $\mathrm{MV}$ and $\mathrm{AV}$, mitral regurgitation was the most common, present in $10(41.7 \%)$ patients, aortic stenosis in 8 


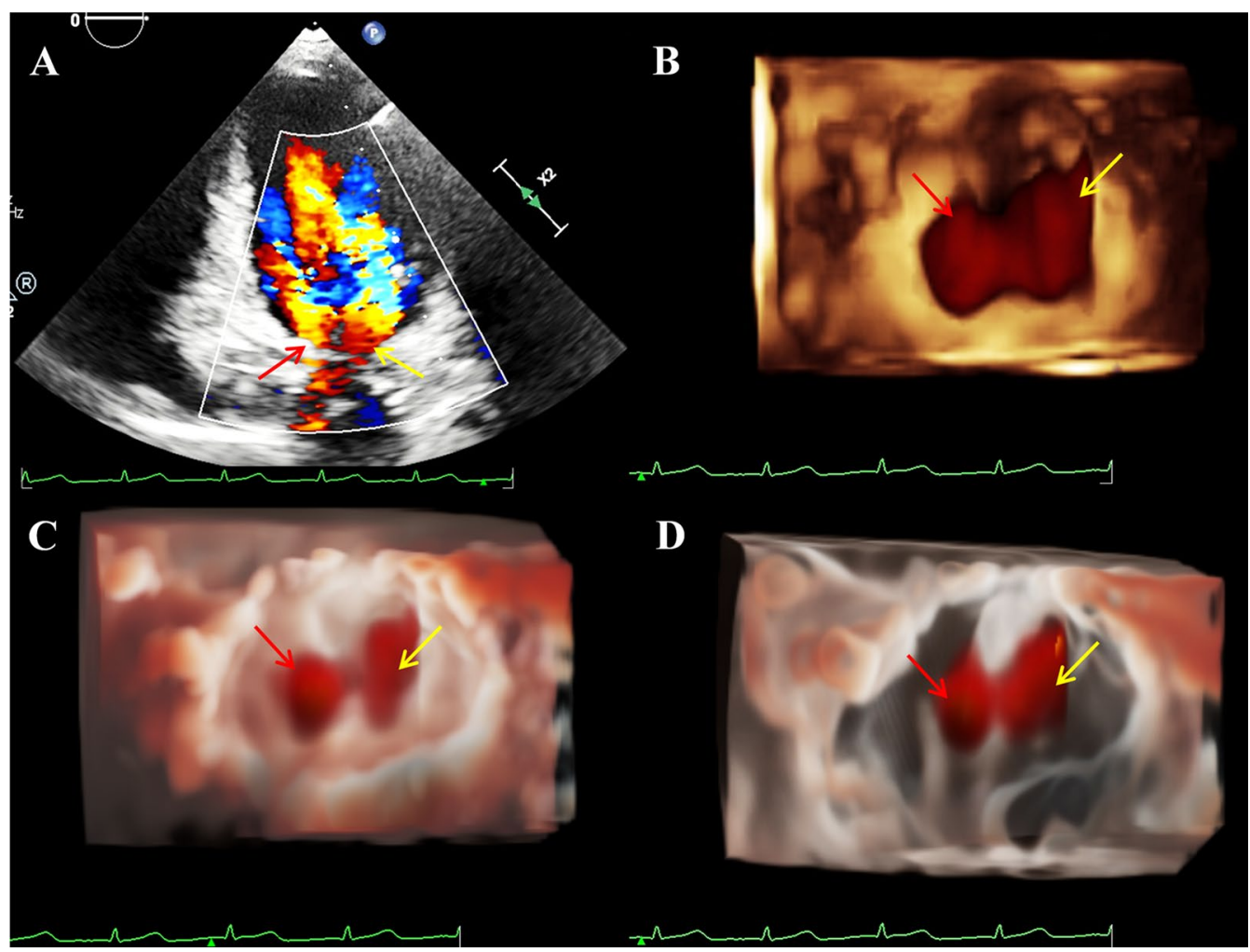

Fig. 4 Two separate diastolic mitral inflow flows. A 2D-TTE color Doppler in the non-standard apical 4-chamber view shows that there are two blood streams flowing through the left atrioventricular channel simultaneously. B-D Traditional 3DE, TrueVue, and TrueVue Glass images showing two jets into the left ventricle. Yellow arrows show jets from orifice 1, red arrows show jets from orifice 2. 2D-TTE two-dimensional transthoracic echocardiogram, 3DE three-dimensional echocardiography

(33.3\%), mitral stenosis in 7 (29.2\%), and aortic regurgitation in 4 (16.7\%). Chordae tendineae was noted in 12 (50.0\%) patients: the chordae attached to each orifice in
5 (20.8\%); accessory septal attachment in $2(8.3 \%)$; parachute chordal attachments in $2(8.3 \%)$; and attachment to the anterior wall, chordal ring, non-elongation, and

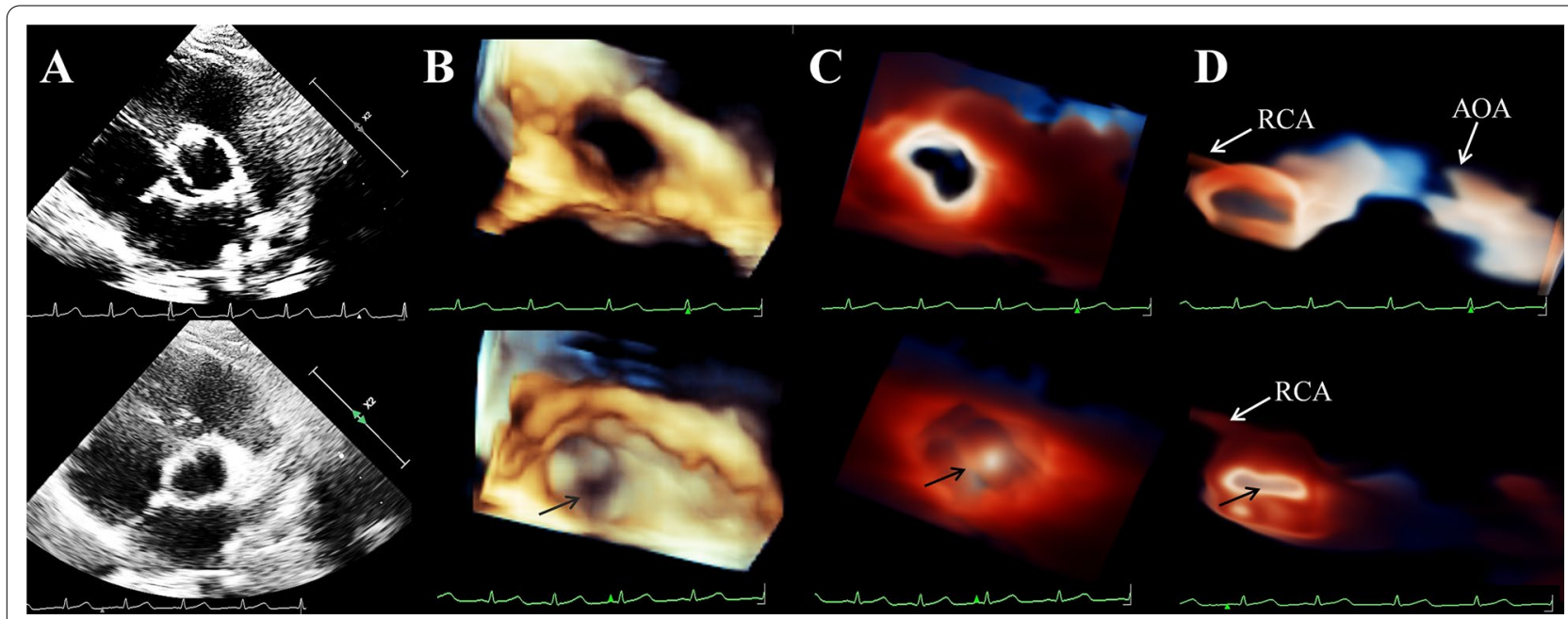

Fig. 5 Bicuspid aortic valve. A 2D-TTE showing the aortic valve during systole (above) and diastole (below). B-DTraditional 3DE, TrueVue, and TrueVue Glass images demonstrating aortic valves when opened and closed, respectively. Black arrows show aortic valve closing line. AOA aortic arch, $R C A$ right coronary artery, 2D-TTE two-dimensional transthoracic echocardiogram, 3DE three-dimensional echocardiography 


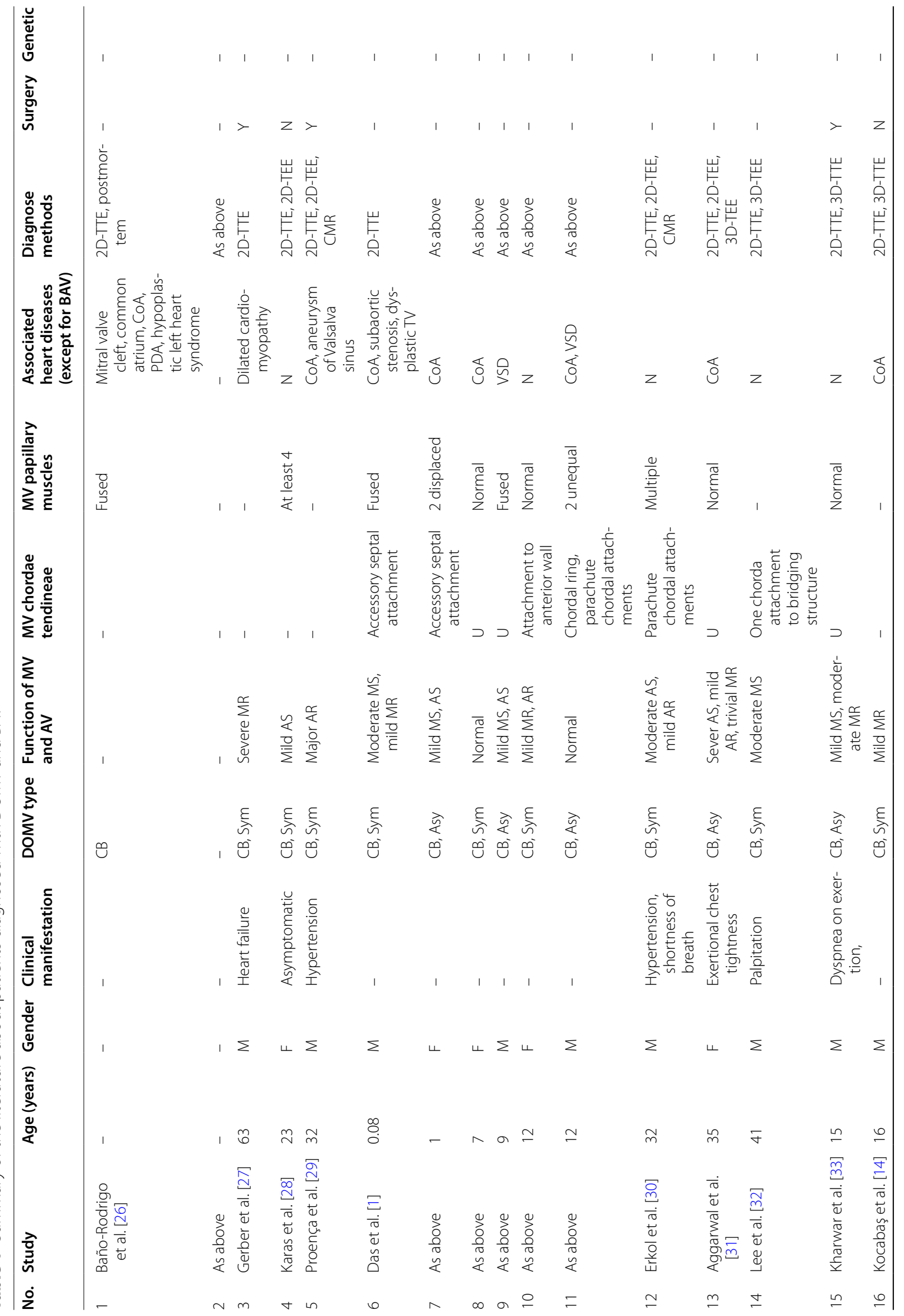




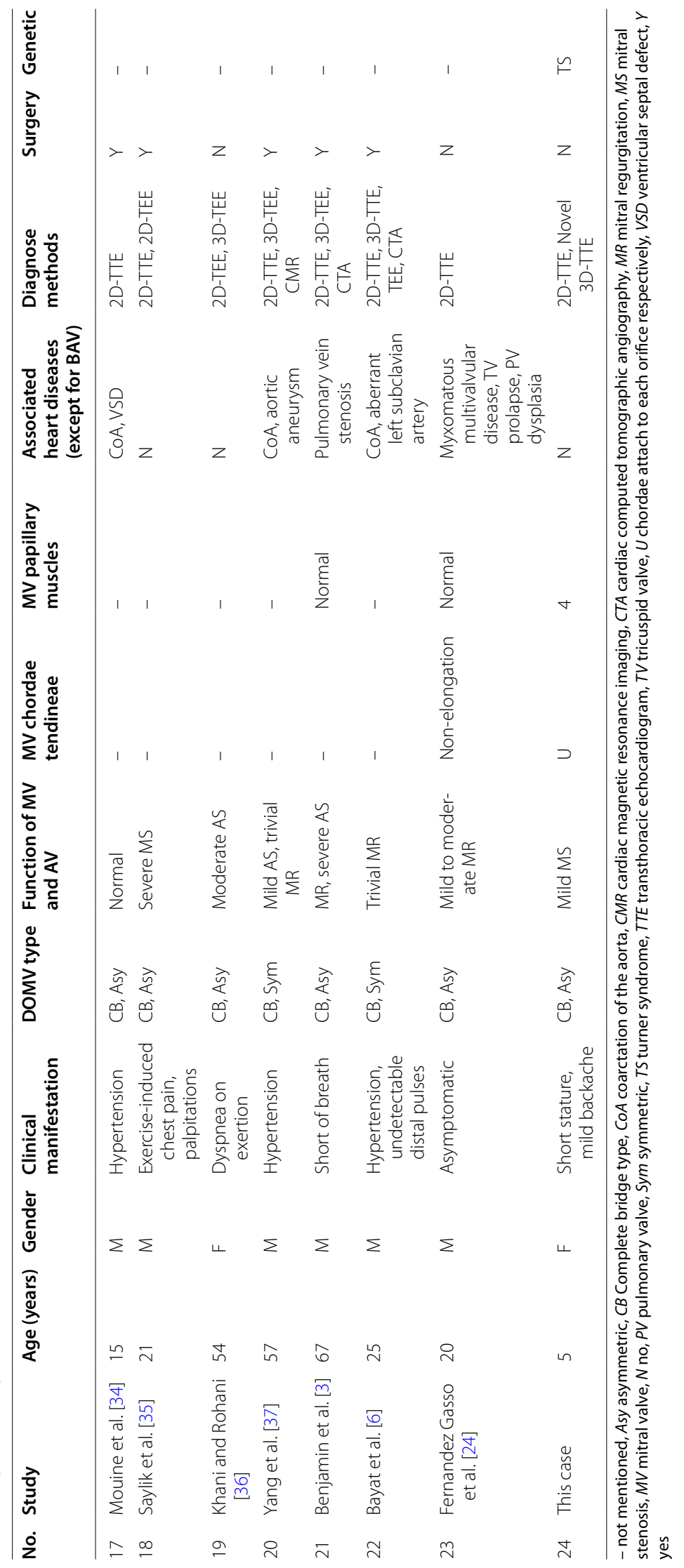


Table 2 Comparison of the advantages and disadvantage of 2DE, traditional 3DE, TrueVue, and TrueVue Glass

\begin{tabular}{|c|c|c|c|c|}
\hline & $2 \mathrm{DE}$ & Traditional 3DE & TrueVue & TrueVue Glass \\
\hline \multirow[t]{5}{*}{ Advantages } & $\begin{array}{l}\text { Provide sectional morphology } \\
\text { images }\end{array}$ & $\begin{array}{l}\text { Display 3D geometry of struc- } \\
\text { tures }\end{array}$ & Advantages of traditional 3DE & Shield the myocardial tissue \\
\hline & \multirow[t]{4}{*}{ High resolution } & $\begin{array}{l}\text { Show spatial position of MV } \\
\text { apparatus }\end{array}$ & Higher resolution & Depict edges of orifices \\
\hline & & \multirow[t]{3}{*}{$\begin{array}{l}\text { Delineate anomalous attach- } \\
\text { ments of the sub-valvular } \\
\text { apparatus }\end{array}$} & $\begin{array}{l}\text { Realistic light and shadow } \\
\text { effects }\end{array}$ & $\begin{array}{l}\text { Show overall aortic valve, arch } \\
\text { and coronary artery in its } \\
\text { entity }\end{array}$ \\
\hline & & & $\begin{array}{l}\text { Simulate the pathological } \\
\text { texture of valves and myo- } \\
\text { cardium }\end{array}$ & $\begin{array}{l}\text { Simulate the thin and translu- } \\
\text { cent leaflets }\end{array}$ \\
\hline & & & & $\begin{array}{l}\text { Show global 3D hemodynamic } \\
\text { characteristics }\end{array}$ \\
\hline \multirow[t]{4}{*}{ Disadvantages } & $\begin{array}{l}\text { Cannot see the spatial structure } \\
\text { characteristics }\end{array}$ & $\begin{array}{l}\text { The texture of the lesion quite } \\
\text { different from the real patho- } \\
\text { logical specimen }\end{array}$ & $\begin{array}{l}\text { Shows that thin valves and } \\
\text { chordae may appear false } \\
\text { echo loss }\end{array}$ & $\begin{array}{l}\text { The scraggly fine texture on } \\
\text { the surface of the anatomi- } \\
\text { cal structure is insufficient to } \\
\text { display }\end{array}$ \\
\hline & $\begin{array}{l}\text { Multiple ultrasound views are } \\
\text { needed to clarify the anatomy } \\
\text { of each component of the } \\
\text { Mitral valve apparatus }\end{array}$ & The level of structure is unclear & \multirow[t]{3}{*}{$\begin{array}{l}\text { Cannot see the surrounding } \\
\text { anatomy through the valve }\end{array}$} & \\
\hline & $\begin{array}{l}\text { The lesion is not intuitive, the } \\
\text { diagnosis depends more on } \\
\text { the experience of the imaging } \\
\text { doctor }\end{array}$ & \multirow[t]{2}{*}{$\begin{array}{l}\text { The boundary is not clear } \\
\text { enough }\end{array}$} & & \\
\hline & Time-consuming and laborious & & & \\
\hline
\end{tabular}

$2 D E$ two-dimensional echocardiography, $3 D E$ three-dimensional echocardiography, $A V$ aortic valve, $M V$ mitral valves

one chorda attachment to the bridging structure were seen in 1 (4.2\%) case each. Papillary muscles were mentioned in 14 cases $(58.3 \%)$. They were normal in $6(25.0 \%)$ and fused in 3 (12.5\%); the morphology was abnormally displaced and unequal in a normal number of papillary muscles in $2(8.3 \%)$, and four or more papillary muscles were noted in 3 (12.5\%). The most complicated malformation was coarctation of the aorta $(n=11,45.8 \%)$. All patients underwent echocardiography, and among them, 10 (41.7\%) underwent transesophageal echocardiography (TEE) and 9 (37.5\%) underwent 3DE. Of the 13 (54.2\%) patients with operation-related information, 8 (33.3\%) underwent operations, although some of them underwent an operation to correct the aortic constriction rather than repair or replace the deformed valve. None of the reported cases involved a genetic syndrome except our case.

An invasive TEE is not usually necessary for diagnosis due to the excellent acoustic window. Clear display of children's valves via traditional $2 \mathrm{DE}$ and $3 \mathrm{DE}$ has certain difficulties due to their thinness, easily leading to misdiagnosis by inexperienced sonographers [17]. TrueVue is a novel 3D rendering mode with high resolution [18]. By changing the position and depth of the light source, realistic light and shadow effects can be obtained while illuminating the target structure, simulating it, including the texture of the double orifices and the sub-valvular apparatus, into photorealistic 3D images. TouchVue provides an operating platform that can effectively improve work efficiency. The TrueVue Glass imaging shields the myocardial tissue, specifically the blood-containing heart chambers and blood vessels, depicting thin BAV in its entirety. Especially when the light source was strategically placed behind the valve, light transmitted from the opening valve clearly revealed that the "fish mouth" bicuspid valve was completely different from the "inverted triangle" of the three-leaflet AV. Even the contour of the aortic arch and right coronary artery lumens were displayed clearly in TrueVue Glass images when viewing the short axis of the $\mathrm{AV}$, which cannot be seen in traditional $3 \mathrm{D}$ or TrueVue images. Color on all three rendering modes showed two exact jets from the left atrium side, confirming the diagnosis of 2D-TTE. The main advantages and disadvantages of these imaging methods developed by Philips company in the diagnosis of this case are summarized in Table 2. Another limitation of these new series of 3D ultrasound techniques is that they require an uncomplicated training of methods and techniques before they can be used effectively. To our knowledge, this is the first case diagnosed with DOMV and BAV using the above series of novel 3DE techniques. 
Lesions of the MV apparatus sometimes occur simultaneously and do not involve just the leaflets [19]. In this case, DOMV was first detected, and then the abnormal number of papillary muscles was noted. BAV can be associated with specific syndromes, like Marfan, William Beuren, Andersen, Bosley-Salih-Alorainy, Athabascan Brainstem Dysgenesis, Turner, and Vascular Ehlers-Danlos syndromes [5]. Furthermore, three DOMV cases with hereditary syndromes (Ellis-van Creveld, Sotos, and Holt-Oram syndrome) have been reported [20-22]. In addition, the fact that BAV occurs more frequently in males and in patients with TS suggests a potential X-linked inheritance [7, 23]. Fernandez Gasso L presented an idea that multivalvular disease may be genetic [24]. Based on these findings, our case may be a hint that multivalvular disease is associated with the $\mathrm{X}$ chromosome.

The patient is not currently undergoing surgery because there is no significant valve regurgitation or stenosis. However, with aging, valve elasticity decreases, which will aggravate valve dysfunction [25]; therefore, long-term follow-up of this patient is essential.

In conclusion, this case extended the possible complex lesions in TS and endorses 3D transillumination rendering techniques in detecting valvular malformations.

\section{Abbreviations}

2DE: Two-dimensional echocardiography; 3DE: Three-dimensional echocardiography; BAV: Bicuspid aortic valve; DOMV: Double-perforated mitral valve; MV: Mitral valve; TS: Turner syndrome; TEE: Transesophageal echocardiography; TTE:Transthoracic echocardiography.

\section{Supplementary Information}

The online version contains supplementary material available at https://doi. org/10.1186/s12872-021-02184-2.

Additional file 1: Video 1. TrueVue Glass color Doppler shows the two streams of blood entering the left ventricle from the left atrium through the double orifice mitral valve, viewed from the side of the left ventricle.

Additional file 2: Video 2 . The short-axis view of the left ventricle shows the two orifices of the mitral valve and the corresponding four papillary muscles simultaneously through the 3D "dual volume" imaging mode.

\section{Acknowledgements}

The authors thank Ms. Shu Yang of Philips Medical Group for technical support.

\section{Authors' contributions}

FS contributed to research design, acquired ultrasound images, analyzed, and interpreted the data. XT drafted the main manuscript and conducted a literature research, FS revised it critically for important intellectual content. AS and XZ collaboratively edited the 3D images or videos and followed up patients and their families. AS obtained the patient's consent. YL collected and analyzed the clinical data. WR guided the acquisition of ultrasound images and provided approval for the submitted final versions. All authors read and approved the final manuscript.

\section{Funding}

This study was supported by grants from Young Scientists Fund of the National Natural Science Foundation of China [81901763 to FS]; Liaoning Provincial Natural Science Key Project of China [20180530064 to FS]; 345 Talent Project [30B-M0282 to FS]. The funding assisted in the collection of clinical data and publication fees.

\section{Availability of data and materials}

All data generated or analyzed during this study are included in this published article.

\section{Declarations}

\section{Ethics approval and consent to participate}

This study was approved by the ethics review board of China Medical University.

\section{Consent for publication}

Written informed consent was obtained from the legal guardian of the patient for the publication of this case report and any accompanying images. A copy of the written consent is available for review by the Editor of this journal.

\section{Competing interests}

The authors declare that they have no competing interests.

\section{Author details}

'Department of Ultrasound, Shengjing Hospital of China Medical University, No. 36 Sanhao Street, Heping District, Shenyang 110004, China. ${ }^{2}$ Department of Cardiac Surgery, Shengjing Hospital of China Medical University, Shenyang, China.

Received: 11 January 2021 Accepted: 28 July 2021

Published online: 04 August 2021

\section{References}

1. Das BB, Pauliks LB, Knudson OA, Kirby S, Chan KC, Valdes-Cruz L, Cayre RO. Double-orifice mitral valve with intact atrioventricular septum: an echocardiographic study with anatomic and functional considerations. J Am Soc Echocardiogr. 2005;18(3):231-6.

2. Barbero U, Ho SY. Anatomy of the atria: a road map to the left atrial appendage. Herzschrittmacherther Elektrophysiol. 2017;28(4):347-54.

3. Benjamin MM, Banga S, Sengupta PP, Mills JD, Hamirani YS. Double-orifice mitral valve associated with bicuspid aortic valve and primary pulmonary vein stenosis. CASE (Philadelphia, Pa). 2020:4(3):152-4.

4. Liu S, Ren W, Ma C, Yang J. Congenital double-orifice mitral valve in asymptomatic patients comprehensive assessment by three-dimensional echocardiography. Int Heart J. 2018;59(1):213-5.

5. Balistreri CR, Forte M, Greco E, Paneni F, Cavarretta E, Frati G, Sciarretta S. An overview of the molecular mechanisms underlying development and progression of bicuspid aortic valve disease. J Mol Cell Cardiol. 2019:132:146-53

6. Bayat F, Namazi MH, Khani M, Shekarkhar S, Fatehi A, Tabary M, Khaheshi I. Double orifice mitral valve in a patient with bicuspid aortic valve and coarctation of the aorta: a rare presentation. Clin Case Rep. 2020;8(6):1021-4

7. Gravholt $\mathrm{CH}$, Viuff MH, Brun S, Stochholm K, Andersen NH. Turner syndrome: mechanisms and management. Nat Rev Endocrinol. 2019;15(10):601-14.

8. Silberbach M, Roos-Hesselink JW, Andersen NH, Braverman AC, Brown N, Collins RT, De Backer J, Eagle KA, Hiratzka LF, Johnson WH Jr, et al. Cardiovascular health in turner syndrome a scientific statement from the American Heart Association. Circ Genomic Precis Med. 2018;11(10):e000048.

9. Lebecque P, Bosi G, Lintermans J, Stijns M, Germanes J, Chalant CH, Vliers A. Myxomatous degeneration of the mitral valve in a child with Turner syndrome and partial anomalous pulmonary venous return. Eur J Pediatr. 1984:141(4):228-30.

10. van Heerde M, Hruda J, Hazekamp MG. Severe pulmonary hypertension secondary to a parachute-like mitral valve, with the left superior caval 
vein draining into the coronary sinus, in a girl with Turner's syndrome. Cardiol Young. 2003;13(4):364-6.

11. Negrea SL, Alexandrescu C, Sabatier M, Dreyfus GD. Cleft posterior mitral valve leaflet in an adult with turner syndrome diagnosed with the use of 3-dimensional transesophageal echocardiography. Tex Heart Inst J. 2012;39(4):547-9.

12. Tamin SS, Dillon J, Aizan K, Kadiman S, Latiff HA. An accessory mitral valve leaflet causing left ventricular outflow tract obstruction and associated with severe aortic incompetence. Echocardiogr J Cardiovasc Ultrasound Allied Tech. 2012;29(2):E34-8.

13. Destefanis P, Barbero U, Luciano A, Salvetti I, Zingarelli E, Casabona R, Pozzi R. The day when the echocardiographist went mushrooming.... J Echocardiogr. 2013;11(1):18-9.

14. Kocabas A, Ekici F, Cetin I, Aktas D. Three-dimensional echocardiographic evaluation of a patient with double-orifice mitral valve, bicuspid aortic valve, and coarctation of aorta. Echocardiogr J Cardiovasc Ultrasound Allied Tech. 2014;31(1):E33-4.

15. Vairo A, Marro M, De Ferrari GM, Rinaldi M, Salizzoni S. Use of a photorealism 3D rendering technique to enhance echocardiographic visualization of the anatomical details during beating-heart mitral valve repair. Echocardiography. 2019;36(11):2090-3.

16. Karagodin I, Addetia K, Singh A, Dow A, Rivera L, DeCara JM, SoulatDufour L, Yamat M, Kruse E, Shah AP, et al. Improved delineation of cardiac pathology using a novel three-dimensional echocardiographic tissue transparency tool. J Am Soc Echocardiogr. 2020;33(11):1316-23.

17. Martin M, Lorca R, Rozado J, Alvarez-Cabo R, Calvo J, Pascual I, Cigarran H, Rodriguez I, Moris C. Bicuspid aortic valve syndrome: a multidisciplinary approach for a complex entity. J Thorac Dis. 2017;9(Suppl 6):S454-64.

18. Vainrib AF, Bamira D, Aizer A, Chinitz LA, Loulmet D, Benenstein RJ, Saric M. Photorealistic imaging of left atrial appendage occlusion/exclusion. Echocardiography. 2019;36(8):1601-4.

19. Sun F, Chen Y, Ren W, Zhang Y, Wu D, Chen X, Ma C, Li D. Four-tiered echocardiographic analysis approach for congenital mitral valve malformations: 4 years of experience. Int J Cardiol. 2017;227:602-10.

20. Kamesui T, Seki M, Tsubota M, Endo M, Watanabe S, Sato H. A case of Ellis-van Creveld syndrome with partial atrioventricular septal defect and double orifice mitral valve. Zasshi I Nihon Kyobu Geka Gakkai. 1997:45(4):589-93.

21. Nakamura A, Horigome H, Ishizu T, Seo Y, Sumazaki R. Double orifice mitral valve combined with left ventricular noncompaction in a child with Sotos syndrome. J Cardiol Cases. 2015;11(3):88-90.

22. Verma KP, Healy S, Teng J, Nerlekar N. An unusual finding of a double orifice mitral valve in a patient with Holt-Oram syndrome. Heart Lung Circ. 2019;28(4):E99-100.

23. Martin M, Lorca R, Rozado J, Alvarez-Cabo R, Calvo J, Pascual I, Cigarran H, Rodriguez I, Moris C. Bicuspid aortic valve syndrome: a multidisciplinary approach for a complex entity. J Thorac Dis. 2017;9:S454-64.

24. Fernandez Gasso L, Jimenez Lopez-Guarch C, Garcia Robles JA, Solis J. Double-orifice mitral valve associated with multivalvular involvement: a new entity? Eur Heart J. 2020;41:2818.
25. Benjamin MM, Banga S, Sengupta PP, Mills JD, Hamirani YS. Double-orifice mitral valve associated with bicuspid aortic valve and primary pulmonary vein stenosis. CASE (Phila). 2020;4(3):152-4.

26. Bano-Rodrigo A, Van Praagh S, Trowitzsch E, Van Praagh R. Double-orifice mitral valve: a study of 27 postmortem cases with developmental, diagnostic and surgical considerations. Am J Cardiol. 1988;61(1):152-60.

27. Gerber IL, Calder AL, Ruygrok PN, Greaves SC, Gibbs HC, Long S, Coverdale HA. Association of a double orifice mitral valve with a bicuspid aortic valve in an explanted heart with dilated cardiomyopathy. Heart Lung Circ. 2003;12(3):188-188.

28. Karas S, Barbetseas J, Lambrou S, Parissis J, Metzikof D, Toutouzas P. Well-functioning double-orifice mitral valve in a young adult. J Clin Ultrasound. 2003;31(3):170-3.

29. Proenca G, Freitas A, Baptista S, Thomas B, Fragata J, Ferreira R. Double orifice mitral valve in an asymptomatic adult with an unusual combination of congenital malformations: a case report. Port J Cardiol Off J Port Soc Cardiol. 2004;23(2):233-6.

30. Erkol A, Karagoz A, Ozkan A, Koca F, Yilmaz F, Sonmez K, Kaymaz C. Double-orifice mitral valve associated with bicuspid aortic valve: a rare case of incomplete form of Shone's complex. Eur J Echocardiogr. 2009;10(6):801-3.

31. Aggarwal G, Schlosshan D, Arronis C, Mathur G, Cranney G. Real-Time 3-Dimensional transesophageal echocardiography in the evaluation of a patient with concomitant double-orifice mitral valve, bicuspid aortic valve, and coarctation of the aorta. Circulation. 2009;120(22):E277-9.

32. Lee GY, Chang S-A, Park SW. Double orifice mitral valve with bicuspid aortic valve in real time three-dimensional transesophageal echocardiographic examination. Echocardiogr J Cardiovasc Ultrasound Allied Tech. 2012;29(9):E253-4.

33. Kharwar RB, Sharma A, Sethi R, Narain VS. Double orifice mitral valve with bicuspid aortic valve evaluation by three-dimensional echocardiography. J Am Coll Cardiol. 2014;63(1):e1.

34. Mouine N, Amri R, Cherti M. Unusual findings in secondary hypertension: double orifice mitral associated to aortic coarctation, bicuspid aortic valve, and ventricular septal defect. Int Arch Med. 2014;7(1):14-14.

35. Saylik F, Mutluer FO, Tosu A, Selcuk M. Double orifice mitral valve and bicuspid aortic valve: pieces of the same single puzzle? Case Rep Cardiol. 2015;2015:305142.

36. Khani M, Rohani A. Double-orifice mitral valve associated with bicuspid aortic valve. Asian Cardiovasc Thorac Ann. 2017:25(5):386-7.

37. Yang LT, Foley TA, Eidem B, Crestanello JA, Michelena HI. Double-orificemitral valve associated and bicuspid aortic valve: forme fruste of Shone's complex? Eur Heart J-Cardiovasc Imaging. 2020;21(1):118-118.

\section{Publisher's Note}

Springer Nature remains neutral with regard to jurisdictional claims in published maps and institutional affiliations.

Ready to submit your research? Choose BMC and benefit from

- fast, convenient online submission

- thorough peer review by experienced researchers in your field

- rapid publication on acceptance

- support for research data, including large and complex data types

- gold Open Access which fosters wider collaboration and increased citations

- maximum visibility for your research: over 100M website views per year

At $B M C$, research is always in progress.

Learn more biomedcentral.com/submissions 